\title{
Assessment towards use of holy water as complementary treatment among PLWHA, Northeast, Ethiopia
}

\author{
Abush Kebede Ketema ${ }^{1}$, Zewdu Shewangizaw Weret ${ }^{2, *}$ \\ ${ }^{1}$ Regional monitoring and evaluation advisor, Management Science for Health, Addis Ababa, Ethiopia \\ ${ }^{2}$ College of medicine and health sciences, Arbaminch University, Ethiopia
}

Email address:

abush.kebede@yahoo.com (Abush. K.), hweret@gmail.com (Zewdu. S.)

\section{To cite this article:}

Abush Kebede Ketema, Zewdu Shewangizaw Weret. Assessment Towards Use of Holy Water as Complementary Treatment among PLWHA, Northeast, Ethiopia. American Journal of Internal Medicine. Vol. 3, No. 3, 2015, pp. 127-131. doi: 10.11648/j.ajim.20150303.16

\begin{abstract}
Background: Holy water use in the form of a drink and a shower is the main treatment used by People living with HIV/AIDS (PLWHA) together with other spiritual practices. A growing number of PLWHA in Ethiopia today are relocating to holy water sites. The study was intended to determine the level of use of holy water as anti-retro viral treatment (ART) among PLWHA. Cross sectional study designs with systematic random sampling through interview among 422 respondents were done in Debrebrihan hospital and health center. Single proportion formula with p- value 0f 50\% used to determine the sample size. Frequency and percentage were computed by the SPSS statically software. A total of 422 respondents was included in the study with a median age of 35 years; most of them were females $262(62.1 \%)$ and $168(39.8 \%)$ were married. Among the respondents $282(66.8 \%)$ had experience of using holy water. The result also shown that, $73(25.9 \%)$ of respondents reported that it is not convenient to take medication while using holy water with spiritual fear of using anti retro viral (ARV) drugs and holy water together $51(69.9 \%)$. The study concludes that, the use of holy water as treatment of human immunodeficiency virus/ acquired immune deficiency syndrome (HIV/AIDS) and more than half of the study participants visit the holy water site because of them believed that it is a result of sanity and punishment from God. Hence, finding implication towards use of mixed treatment for to adherence via proper advocacy, training and opening culturally appropriate treatment site is as a key fact regarding drug adherence in the treatment of PLWHA.
\end{abstract}

Keywords: Adherence, Traditional, Alternative medicine, Antiretroviral drugs, Spiritual

\section{Background}

AIDS remains the leading cause of mortality worldwide and primary causes of death in sub Saharan Africa. From estimating new infections in 2007 two third occurred in sub Saharan Africa. More than 68\% adults and nearly $90 \%$ children infected with HIV live in this region, and more than $76 \%$ AIDS death in 2007 occurred there, illustrating the unmet need for antiretroviral treatment in Africa. ${ }^{1}$

The world at large, with various social and health problems is demanding remedies that would help improve the lives of citizens. HIV/AIDS is one of the greatest challenges of this century compels nations to respond to the situation in whatever way is possible. ${ }^{2}$

A study done in Tanzania on religious beliefs influences on HIV shows religious beliefs strongly influence the way many Tanzanians think about HIV/AIDS and a significant percentage of people believe that people who are HIV infected have not followed the word of God, that, HIV is a punishment from God. Most participants (84.2\%) said that they would disclose their HIV status to their pastor of the congregation if they became infected. ${ }^{3}$ Another study done on faith leaders also shows praying for the sick was a common practice and over one third of respondents said that prayer could cure HIV.

Ethiopia is one of a developing country in which use of traditional medicine for primary health care is used by about $90 \%$ of the population. ${ }^{5}$ Traditional, complementary and alternative medicine (TCAM) is commonly practiced by PLWHA and $95 \%$ of health care providers were not aware that their patients were taking traditional treatment. ${ }^{6}$

Spirituality and religion considered as central issues for patients dealing with chronic illness. Most patients with HIV/AIDS belong to an organized religion and use their religion to cope with their illness ${ }^{7}$

Thousands of Ethiopian AIDS patients risk their life by refusing medication in favor of holy water. ${ }^{8}$ 
Holy water use in the form of a drink and a shower is the main treatment used by the PLWHAs together with other spiritual practices. People in most cases are in need of compromising the spiritual practices together with the medical knowledge through counseling or other models, which are not available, let alone to access and utilize. At the same time due to the widespread poverty, this section of the population is also affected very much. Fulfilling basic needs is difficult to most of them. In addition the social isolation from their families' relatives and friends is very common to the majority of these communities. ${ }^{2}$

According to federal HIV/AIDS prevention and control office (FHAPCO) progress report for Ethiopian orthodox, holy water is a traditional cure for disease and ailments. Followers' regularly gather at more than 160 sacred sites across the country where they can drink holy water and be baptized as treatment for all types of afflictions. Since the start of the HIV pandemic, infected and affected Ethiopians have sought the healing power of holy water and flocked to these holy sites by the thousands if not hundreds of thousands in search of a cure, often while abandoning their ART. ${ }^{9}$

A growing number of people, living with HIV/AIDS in Ethiopia today are relocating to holy water sites in search of spiritual care. The use of holy water is considered by them to be an alternative and complementary treatment for HIV/AIDS. ${ }^{10}$ There are people who believe that the only solution to HIV/AIDS is holy water and they do not want to use the ART and a majority of holy water users believe that HIV/AIDS caused by an evil spirit or a demon by itself. Lack of awareness of serious health problem and encouraging of religious leaders to use holy water are considered to be a reason to stop taking medication. ${ }^{11}$

Desperate Ethiopians, flocking to an ancient mountain north of the capital, Addis Ababa, seeking a "holy water" cure for AIDS have been belatedly warned by the church to keep taking their antiretroviral medication. Thousands of HIV-positive people from all corners of Ethiopia have visited Entoto Mountain on the Northern outskirts of the capital, after local priests promised they could cure the virus. ${ }^{5}$

According to Embassy of the United States Addis Ababa, Ethiopia, 2007 reports after discussion with Ethiopian patriarch at the issue of modern versus traditional methods in treating HIV/AIDS, there is a high number of patient uses holy water as choice of treatments. Hence, the meeting emphasized to advocate for the dual use of treatments. ${ }^{12}$

"A majority of holy water users believes that either HIV/AIDS is caused by an evil spirit or it is a demon by itself," said Ato Zena Berhanu, a PhD student in Addis Ababa who has researched the issue. "There are people who believe that the only solution to HIV/AIDS is the holy water and they do not want to use the antiretroviral drugs. ${ }^{5}$

A concerted effort was needed to ensure people remain on their drug regimens, even if they used the holy water. "Entoto "and other holy water sites in other parts of the country are attracting thousands of people living with HIV/AIDS. There should be some organized effort to address the problems of these citizens in a culturally sensitive manner; this includes encouraging people to combine holy water and ARV drugs, and designing and implementing a care program for the patients. $^{5}$

Due to the high influx of PLWHA into the holy water site area, JHU-Tsehai has opened a chronic care clinic two kilometer from the Holy Water site, and has begun providing anti-retroviral care and treatment services to a growing population of holy water recipients, enabling HIV positive individuals who come there to get well enough to return home and continue treatment at one of over hundred united states president's emergency plan for AIDS relief (PEPFAR) supported ART clinics throughout the country. ${ }^{12}$

Even though, studies done on HIV/AIDS treatment adherence and its correlates. Nevertheless, there is a little study and reports were done on the issue of the use of holy water as a treatment of choice with or without of ART drugs. Therefore, this study aimed at assessing the magnitude of the holy water user among PLWHA at Debrebrihan referral hospital and health center, Debrebrihan, Ethiopia.

\section{Methods}

This cross sectional institution based quantitative data collection technique was used for the study among participant who were taking highly active anti-retroviral therapy (HAART) at Debrebrihan hospital and health center, Northeast, Ethiopia. The sample size was calculated using single population proportion estimates with margin of error $0.05 \&$ proportion of event occurrence at $50 \%$ with $10 \%$ of non-response rate. Based on the above assumption the minimum sample size required for the study was 422 .The study subjects were selected using systematic random sampling techniques from patient registration chart of ART service provision health facilities for the specific day. A structured, pre- tested questionnaire was used for interviewing of study participants to collect the quantitative data from study subject and data collected by trained nurses whom works at ART clinic. Data were cleaned, checked, coded, and entered via EPi Info $7^{\text {th }}$ and analyzed by SPSS version 16 software. Use of holy water was taken as an outcome over other social, demographic and cultural characteristics. Ethical clearance was granted from Amhara Regional State Health Bureau (ARHB) and the zonal health bureau. Moreover, study participants were informed and their confidentialities were kept entire the study. Lastly, the results were disseminated to the responsible bodies' which were an involvement in the health care activities of people living with PLWHA.

\section{Results}

\subsection{Demographic Characteristics}

A total of 422 patients was involved in the study and the response rate was $100 \%$. The respondents median age was 35 years; most of the respondents were females $262(62.1 \%)$ and 168 (39.8\%) were married. Regarding educational status 201 $(47.7 \%)$ has completed primary education. The majority were 
Orthodox Christian 390 (92\%). 354 (83.9\%) were living in town and $368(87.2 \%)$ were unemployed.

\subsection{Socio-Cultural Characteristics}

Fifty two $(12.7 \%)$ of the respondents faces a problem to take medication according to the schedule while they were attending spiritual places due to the fear of taking ARV drugs at religious place 25 (48.1\%). Two hundred ninety-one (69\%) respondents used other (traditional, convectional) medication in addition to HAART to treat HIV and associated problems. The main reason of using those medicines was to treat opportunistic infection (OI) 101 (34.7\%), whereas others were for spiritual relief $100(34.4 \%)$, and to treat side effect $47(16.2 \%)$. Two hundred fifty two $(59.7 \%)$ said that they have practiced fasting, among these 122 (48.4\%) said that medication schedule didn't fit with their fasting period and $60(49.2 \%)$ take without food, $54(44.2 \%)$ shift the time while $8(6.6 \%)$ See table 2 below.

Table 1. Socio demographic and economic characteristics of the study participants Debrebrihan referral hospital and health center Northeast Ethiopia, 2012

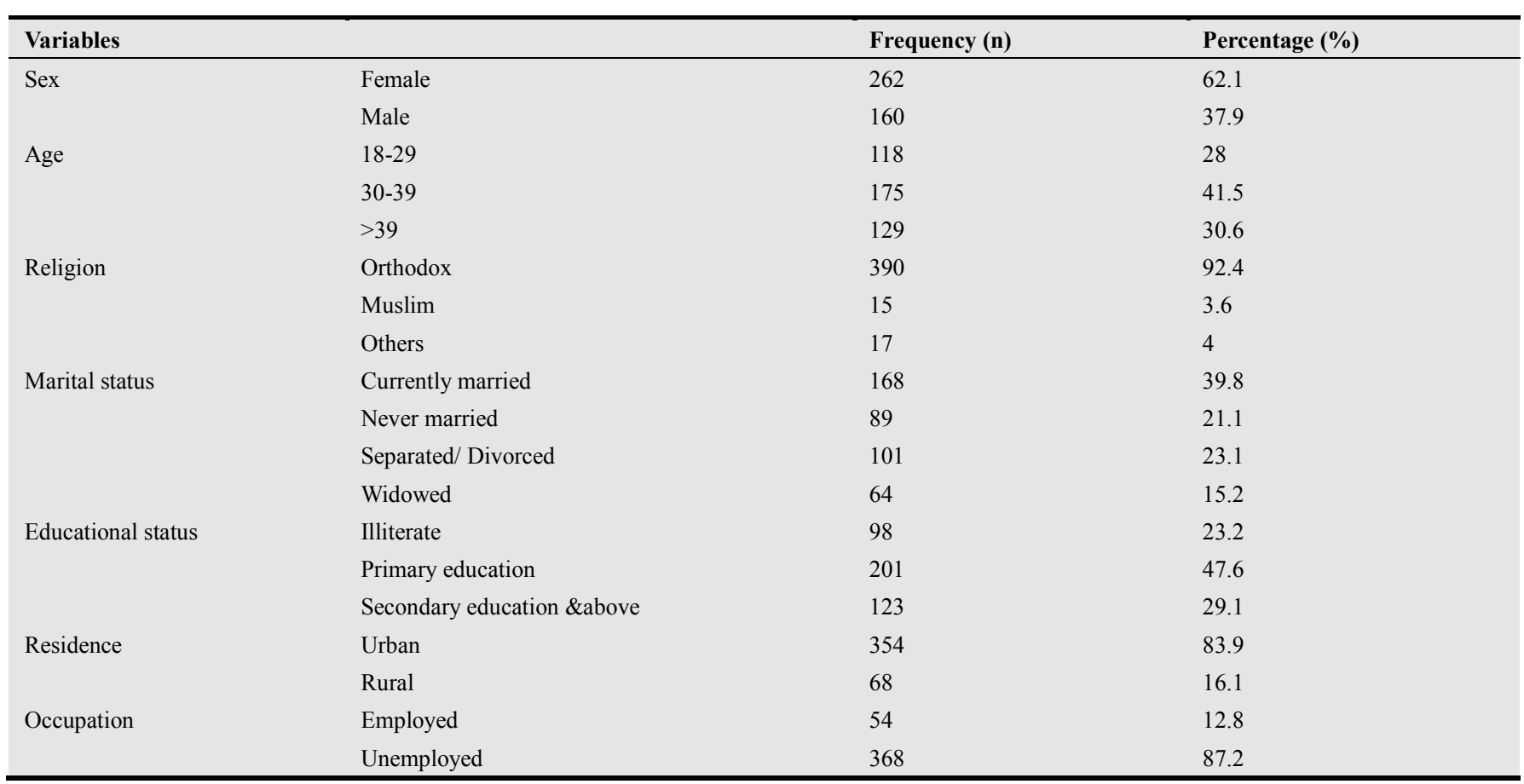

\subsection{Prevalence of holy water use among PLWHA}

Among the respondents $282(66.8 \%)$ had experience of using holy water while they were taking ARV drugs and the rest $33.0 \%$ of respondent were not used holly water as a treatment choice while taking ART treatment. The result also shown that, $73(25.9 \%)$ of respondents reported that it is not convenient to take medication while using holy water with spiritual fear of using ARV drugs and holy water together 51 $(69.9 \%)$ according to figure 1 and table 2 below.

Table 2. Socio cultural characteristics of respondents at Debrebrihan referral hospital and health center, Northeast Ethiopia, 2012

\begin{tabular}{|c|c|c|c|}
\hline Variables & & Frequency (n) & Percentage (\%) \\
\hline \multirow[t]{2}{*}{ Disclose HIV status to others } & Yes & 357 & 84.6 \\
\hline & No & 65 & 15.4 \\
\hline \multirow[t]{2}{*}{ Emotional/ practical support } & Yes & 267 & 63.3 \\
\hline & No & 155 & 36.7 \\
\hline \multirow[t]{2}{*}{ Used complementary treatment } & Yes & 291 & 69 \\
\hline & No & 131 & 31 \\
\hline Type of complementary Treatment & Traditional & 282 & 96.9 \\
\hline \multirow[t]{2}{*}{ Attend Religious place } & Yes & 411 & 97.4 \\
\hline & No & 11 & 2.6 \\
\hline \multirow[t]{2}{*}{ Conduct fasting } & Yes & 252 & 59.7 \\
\hline & No & 170 & 40.3 \\
\hline \multirow[t]{2}{*}{ Believe that cured with prayer } & Yes & 206 & 48.8 \\
\hline & No & 216 & 51.2 \\
\hline Believe HIV is the sin of punishment from God & Yes & 160 & 37.9 \\
\hline
\end{tabular}

Notes: ** Use of conventional medicine was excluded from traditional complementary treatment since mostly provided by health facility Abbreviations: HIV, Human Immune Virus 


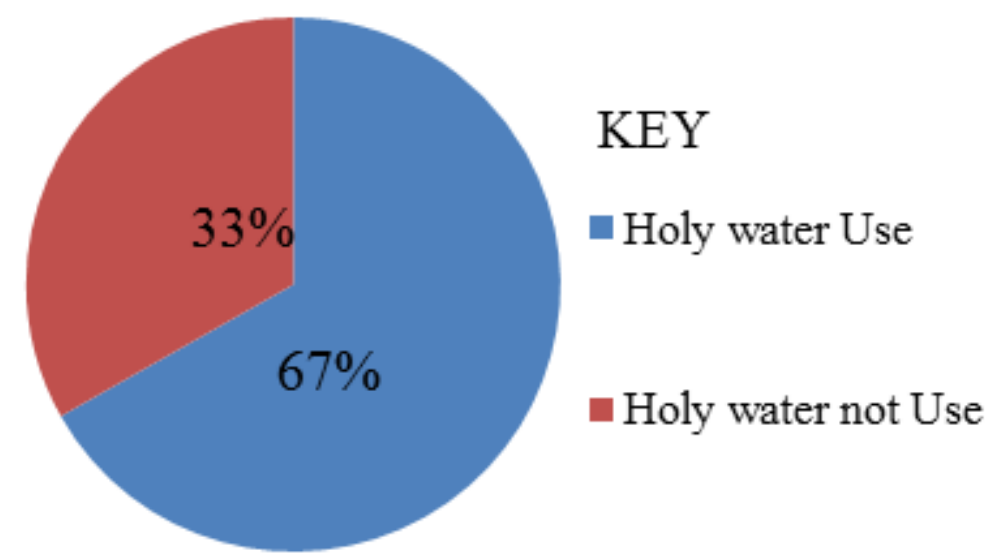

Figure 1. Prevalence of holy water use among PLWHA at Debrebrihan Hospital and health center, Northeast Ethiopia, 2012

\section{Discussion}

The use Holy water use in the form of a drink and a shower is the main treatment used by the PLWHAs together with other spiritual practices. ${ }^{2}$ Literature shows that, a growing number of people living with HIV/AIDS in Ethiopia today are relocating to holy water sites. ${ }^{10}$ This study support previous studies, reports and analysis that there is a prevalence of $291(68.9 \%)$ holy water use in the study area. Even if the exact magnitude not indicated, according to IRIN humanitarian news and analysis in May 2007 shows that, there is thousands of HIV-positive people from all corners of Ethiopia have visited Entoto Mountain, on the northern outskirts of the capital, after local priests promised they could cure the virus. ${ }^{10}$ It also added that concerted effort was needed to ensure people remained on their drug regimens, even if they used the holy water. "Entoto and other holy water sites in other parts of the country are attracting thousands of people living with HIV/AIDS. ${ }^{10}$ There should be some organized effort to address the problems of these citizens in a culturally sensitive manner; this includes encouraging people to combine holy water and ARV drugs, and designing and implementing a care program for the patients. ${ }^{10}$ Other report also supported that there is large number of patients visits different area of spiritual sites which have holly waters because of there is believe that HIV AIDS related to it is a punishment of God for sanity they come to this area, due to this after dual meeting held with embassy of the United states(US) with Ethiopian patriarch in 2007, the US embassy of Ethiopia reports there is high number of patient uses holly water as choice of treatments, hence the meeting were emphasis to advocate to the dual use of treatments. ${ }^{12}$ Therefore, this study has similar implication through figuring out of previous reports in terms of numerical magnitude in evidence based scientific finding. This study also shows how much there is a need to create There should be some organized effort to address the problems of these citizens in a culturally sensitive manner; this includes encouraging people to combine holy water and ARV drugs, and designing and implementing a care program for the patients. This report also agrees with JHU-Tsehai, i.e. opened a chronic care clinic two kilometer from the Holy Water site, and has begun providing anti-retroviral care and treatment services to a growing population of Holy Water recipients, enabling HIV positive individuals who come there to get well enough to return home and continue treatment at one of over hundred PEPFAR-supported ART clinics throughout the country. ${ }^{11}$

Spiritual options may be interpreted as superior alternative and contribute to hampering adherence to ART. Consistently with another study ${ }^{3}$, this study found spiritual believes 206 (48.8\%) respondents believe that prayer can cure HIV, 160 (37.9) agreed that HIV is a result of sin/punishment from God were observed.

Having the strength of addressing adherence and associated factors using quantitative approaches, i.e., this study had its own limitations. The cross-sectional nature of the study couldn't be able to address the temporal and causeeffect relationships between various factors and adherence. Moreover, adherence is a dynamic process which couldn't be predicted at a single point in time, but the study measured snapshot pictures of adherence and factors affecting adherence. Even though this study tried to minimize, social desirability bias, Self- reported adherence was thus likely to overstate true adherence than other methods of measuring adherence. This in fact necessitates the inclusion of other methods of measuring adherence to support consistency of reported rate.

\section{Conclusion}

The study conclude that there is significant use holy water among PLWHA .i.e. nearly to two-third of them, use holy water as treatment of HIV and visit the holy water site due to their believe about HIV is a result of sanity and punishment from God. Thus, most of the study participant to use holy water at treatment choice, some of them didn't use ART drug while they use holly water due their fasting schedule while take holly water and they discontinue their treatment. The findings have also important implication in the use of mixed treatment for drug adherence through appropriate encouragement, training and culturally appropriate nearby treatment site which is nearby at holy water site will decrease 
ART drug non adherence and positive use of TCAM among PLWHA.

\section{Acknowledgments}

Amhara Regional Health office and ART clinic health workers for their unreserved contribution for the realization of the study.

\section{References}

[1] UNAIDS and WHO. AIDS epidemic update. Geneva; 2007 December.

[2] Lelisa Sena, Care and support and people living with HIV and AIDS at Holy water: An assessment at four selected sites in Addis Ababa, Journal of HIV/AIDS \& Social Services 07/2010; 9:260-280

[3] James Zou, Yvonne Yamanaka, Muze John, Melissa Watt, Jan Ostermann, Nathan Thielman: Religion and HIV in Tanzania: influence of religious beliefs on HIV stigma, disclosure and treatment attitudes, BMC public health. 2009 March 4; 9:75. Available from: http://www.biomedcentral.com/14712458/9/75.

[4] Maria Roura, Roy Nsigaye, Benjamin Nhandi, Joyce Wamoyi, Joanna Blusza, Mark Urassa et al,. "Driving the devil away": qualitative insights into miraculous cures for AIDS in a rural Tanzanian ward. BMC public health. 2010; 10:427. Available from: http://www.biomedcentral.com/1471-2458/10/427.
[5] WHO (2002). Traditional medicine growing needs and potential. May 2002, Geneva.

[6] Karl Peltizer, Natalie Friend-du Preez, Shandir Ramalagan, Henry Fomundam and Jane Anderson. Traditional complementary and alternative medicine and antiretroviral treatment adherence among HIV patients in Kwazulu-natal, South Africa. Afr. J. Tradition CAM. 2010; 7(2):125-137.

[7] Sian Cotton, Chrisina M Puchalski, Susan N. Sherman, Joseph M., Mrus, Amy H. Peterman, et al. , spirituality and religion with patients with HIV/AIDS. J Gen Intern Med 2006; 21 :S513 .

[8] IanWoods,Skycorrespondent,http://shegertribune.blogspot.co $\mathrm{m} / 2011 / 12 /$ thousands-of-ethiopian-aids-patients.html.

[9] FHAPCO. Report on progress towards implementation of the UN Declaration of commitment on HIV/AIDS. Addis Ababa; 2010 March.

[10] Humanitarian news and analysis, a service of the UN Office for the Coordination of Humanitarian Affairs, ENTOTO, 25 May 2007 (IRIN).

[11] Plus News Ethiopia: church endorses 'holy water' and antiretroviral as people flock to miracle mountain. 2007 May 25Availablefrom:http://www.plusnews.org/report.aspx?Report ld $=72375$

[12] Patriarch and U.S. Ambassador Discuss Modern Versus Traditional Methods in Treating HIV/AIDS, May 23, 2007; No. 30/07). 